\title{
American ETD dissemination in the age of open access ProQuest, NoQuest, or allowing student choice
}

A stark incongruity in the treatment of academic scholarship persists on many U.S. campuses today. Faculty authors are generally free to publish in whatever vehicle suits their needs and goals, while also expected (or mandated) to deposit their works in the open access university repository. By contrast, graduate students typically must send their scholarship to a single commercial publisher for toll-access, while also required to submit their works to the university repository. ${ }^{1,2,3}$ For faculty, values of academic freedom, author rights, and disciplinary best practices govern their publishing choices. For graduate students, compliance with ProQuest submission mandates is necessary to graduate.

Exploring the reasons for treating our newest scholars so differently from their faculty advisors is beyond the scope of this column. Instead, the focus here is on those institutions that have recognized the importance of student publishing choice as a pedagogical and ethical value. This article highlights examples where graduation requirements have changed to better serve all authors on campus, while also benefitting readers who find value in students' unique works of scholarship. The author's sole aim is to spur discussion on U.S. campuses about electronic thesis and dissertation (ETD) submission and dissemination practices in order to advance graduate education and to improve worldwide access to graduate research.

ProQuest mandates for ETDs no doubt come from well-intended university administrators. But student reactions to these policies appear to be mixed. Some want to market their works through an established dissertation reseller, attracted by the prospect of revenue from sales. This view was recently reflected by Ed.D. recipient Will Deyamport, tweeting his appreciation for possible royalties earned. ${ }^{4}$

Other recent graduates tweet their pleasure at seeing their works "published," evidently accepting ProQuest's claim that assigning an ISBN to the ETD equals publication. ${ }^{6}$

Yet other students strongly oppose university policies mandating ProQuest submission, seeing a glaring contradiction to the values of the open access movement, where scholarly literature is expected to be "online,

Gail P. Clement is scholarly communication librarian at Texas A\&M University, e-mail: gclement@library. tamu.edu

Contact series editors Zach Coble, digital scholarship specialist at New York University, and Adrian Ho, director of digital scholarship at the University of Kentucky Libraries, at crlnscholcomm@gmail.com with article ideas

(0) 2013 Gail P. Clement 
free of charge, and free of most copyright and licensing restrictions." At Texas A\&M, for example, a doctoral student requested a policy change as a "conscientious objector," spurring discussions about graduate requirements across the university. In his letter of protest, the student wrote:

I have serious concerns about signing this [ProQuest submission] form, not from a perspective of my personal research and its availability, but from one of open access, the role of public universities, and leadership on policymaking.... It seems coercive at best, to require students to support ProQuest in order to earn their degree. ${ }^{8}$

He received a waiver.

The questionable benefits of ProQuest submission are also reflected by a graduate student in medical physics who posted to the Student Doctor Network Forum: ${ }^{9}$

Microfilm is clearly obsolete at this point. Generally in physics, students will post their theses and dissertations to arXiv.org, which is considered the definitive repository of "non-journal" literature and e-prints. ... I am considering filing a waiver request because it doesn't seem like a very good bang for the buck.

After an online exchange with a ProQuest representative, this student shared his happy ending:

After reading my letter, the dean not only granted my request, but met with the university level graduate committee and they have now removed the ProQuest requirement for all students. My main objection was that they were forcing the students into a commercial relationship with a third party (ProQuest) in order to graduate. Basically ProQuest offered the university a business deal with seemingly nice terms at the expense of the students, though I'm of the impression that the university never understood this.

Similar concerns are echoed in graduate students' tweets from across the country. ${ }^{10}$

In light of student objections, some universities are reconsidering ETD policies to allow for student choice. For example, the new ETD program at Johns Hopkins University requires submission to the university repository but leaves ProQuest optional. This policy reflects the principles of the university's Ph.D. Board, who noted, "For some students, ProQuest adds value, so those students should be free to participate. But for other students, ProQuest represents an obstacle that should be removed."11

The Georgia Institute of Technology switched to a ProQuest-optional policy in Fall 2012 after receiving complaints about the ProQuest agreement students were required to sign. As reported by Fred Rascoe, writing in the Journal of Librarianship and Scholarly Communication, librarians met with decision makers in the Graduate School and the Office of Legal Affairs "to discuss the implications of these complaints and decide on the policy. The Office of Legal Affairs gave input that there was no requirement to mandate students to enter into an agreement with ProQuest (or any other third party) as a condition of graduation." ${ }^{12}$ Concerns about diminishing Georgia Tech's presence in the ProQuest database were assuaged with the recognition that their SMARTech repository held 100 percent of their theses and dissertations, while ProQuest held just 35 percent and "would never catch up." Georgia Tech came to the conclusion that not requiring submission to ProQuest "would not lead to any significant deficit in coverage, discoverability, or dissemination." ${ }^{13}$

Johns Hopkins and Georgia Tech are among a growing cadre of U.S. research universities now allowing graduate students to choose whether to submit to ProQuest. Others include Stanford University, University of Texas-Austin, University of Georgia, 
University of Michigan, Louisiana State University, and University of Tennessee. A growing list maintained by the author tracks schools once their policy shift has been announced and verified in written documentation. ${ }^{14}$ Additionally, the list is starting to include schools that have historically allowed doctoral students to choose how to meet the university's requirement to publish their work, be it through ProQuest or elsewhere.

For example, the University of HawaiiManoa's policy states, "Students may publish through either ProQuest or an alternative publisher." ${ }^{15}$ Not included on the list are another two major research universities that have verbally confirmed their recent change to ProQuest optional status, but whose written documentation is still in transition.

During campus discussions about changing ETD dissemination policy, the misconception that ProQuest is the only place to effectively search for and retrieve U.S. ETDs remains an issue that student-choice advocates frequently encounter and dispel. They point out that, vendor marketing claims and LibGuide descriptions to the contrary, the collection of U.S. graduate works developed by University Microfilms and its successor ProQuest is not, and has never been, complete. There are various reasons for this circumstance. First, coverage of U.S. master's theses by UMI/ProQuest has never been substantial. Although the Association of Research Libraries did, in the early 1950s, endorse microfilming as one effective method (among several) to distribute dissertations, members did not consider masters' theses worthy of the same treatment. ${ }^{16}$ Second, not all universities have joined the UMI microfilming program, and those that have sometimes withhold dissertations.

Witness the case of Texas A\&M, where library staff analyzed ProQuest dissertation holdings in advance of a digitization project and discovered several hundred titles missing from the company's vaults. Third, some institutions send only partial data. At MIT, for example, students must limit ProQuest submissions to just metadata and abstracts.
The ProQuest database is therefore missing more than 600 full-text works annually from that research powerhouse. Similarly, the University of Florida-the nation's third largest graduate program-policy allows (but does not require) metadata-only submission to ProQuest. ${ }^{17}$

Given the growing trend in ProQuestoptional policies at top research universities, it seems clear that ProQuest coverage of U.S. ETDs is decreasing. Prior research established that UMI records for U.S. dissertations were not complete as of the early 1970 s $^{18}$ and more recent analysis confirms that the incompleteness of coverage persists today. ${ }^{19}$ National Science Foundation data indicates that the total output of U.S. research dissertations between 1957 and 2011 equals 1,770,399 titles; searches in ProQuest's Digital Dissertations database retrieve only 901,478 full-text records-about 51 percent of the number produced nationally. ProQuest does hold minimal citation records for other ETDs not in full text, but the simple citation available for these works may be insufficient to support effective searching.

How can graduate students gain the greatest exposure for their scholarship in a post-ProQuest world? There are many effective options. Most common is dissemination through their university's own digital repository. Not only do ETDs in open access repositories see immediate exposure through search engines such as Google and Google Scholar, they also can be made harvestable by ETD-specific discovery platforms such as the Union Catalog of the Networked Digital Library of Theses and Dissertations (ndltd.org) and the Open Access ETD portal (OATD.org). At some institutions, ETDs in the digital repository are also included in inter-institutional ETD databases such as OhioLink's ETD Center and Texas Digital Library's Texas ETD Repository.

Additionally, access to ETDs through federated scholarship services, such as Primo or Digital Commons Network, provide even greater reach. Finally, ready discovery of ETDs submitted to free popular scholarly 
sites such as Figshare, arXiv.org, SSRN, Academia.edu, or the author's own Web site or blog, enhances exposure to open access theses and dissertations.

The divide between campus interests in mandating ProQuest submission, and student preference for publishing choice, is a difficult one to bridge. Librarian roles may demand advocacy for open access to faculty works on the one hand and justification for toll access to graduate research on the other. Administrative pressures to sustain ProQuest mandates may continue to rise as the company strategically devises new services and tools marketed to campus deans and provosts. For example, the company's new Dissertation Dashboard Concept promises convenient displays of student productivity and ETD usage, ${ }^{20}$ incentivizing administrators to continue requiring ProQuest submission to make these tools more effective for internal institutional uses. But whether or how concierge services from a commercial ETD reseller translate to better educational experiences or publishing successes for graduate students remains to be seen.

ETD author choice would seem to be a key component of quality graduate education in the age of open access. That view prevailed at the 2013 United States Electronic Thesis and Dissertation Association (USETDA) conference, where keynote speaker and Pomona College Professor Char Miller highlighted examples showing that open access publishing strengthens pedagogical objectives. It "grants privilege and power to student authors, gives them space to assert their intellectual agency, allows them to enter the academic conversation, and...maybe even alter some professorial paradigms." ${ }^{21}$ Miller emphasized that students must have the capacity to produce and distribute their ideas and arguments with the same kind of open access that faculty enjoy. Why not allow them the same choices?

The principle of student choice in thesis dissemination was enthusiastically embraced at USETDA by the graduate school professionals and librarians in attendance. Perhaps it is time to extend the vision to all our campuses, reflecting our shared commitment to meaningful 21st-century education, academic freedom, and improving the scholarly communication system.

\section{Notes}

1. Data from the Registry of Open Access Repositories Mandatory Archiving Policies (ROARMAP) reflects hundreds of U.S. institutions with faculty and/or ETD mandates. See http://roarmap.eprints.org/view/geoname /geoname $=5 \mathrm{~F} 2=5 \mathrm{FUS} \cdot \mathrm{html}$ and http: $/ /$ roarmap . eprints.org $/$ view $/$ type $/$ thesis $=5$ Fmandate.$h t m l$.

2. Survey data from CNI indicates 69 percent of member institutions submit ETDs to university repository and about 47 percent submit ETDs to ProQuest (Joan K. Lippincott and Clifford A. Lynch. "ETDs and Graduate Education: Programs and Prospects," Research Library Issues: A Bimonthly Report from ARL, CNI, and SPARC, no. 270 (June 2010): 6-15. See www.arl.org/resources/pubs/rli/archive /rli270.shtml and https://docs.google.com /spreadsheet/ccc?key=0AtSglIhGWCkpdHJ vOUNSZUZyRC04UXRUa0w3UmgtYWc\&us $\mathrm{p}=$ sharing.

3. Additional data about University ProQuest mandates is available from the spreadsheet of ETD program data maintained by subscribers to the ETD-L discussion list. See https://docs.google.com/spreadsheet/ccc?ke $\mathrm{y}=0$ AtSglIhGWCkpdHJvOUNSZUZyRC04UXR Ua0w3UmgtYWc\&usp=sharing.

4. Will Deyamport (Dr. Will), "I get a cut of what they charge. Something wrong with that?" October 1, 2013, 10:17 a.m. Tweet.

5. Caitlin E. Brown (Caitlinebrown), "Oh hey, look at that. I'm published! (in ProQuest)," October 1, 2013, 10:12 pm. Tweet.

6. ProQuest (ProQuest), "Our view is that diss are published, since we assign an ISBN. This differs from monograph and journal publishing of course," September 19, 2013, 8:10 a.m. Tweet.

7. Peter Suber, Open Access (Cambridge: MIT Press, 2012), 4.

8. The full text of his "Graduate Student Manifesto" is available online at http://sites.tdl. org/fuse/?p=31. 
9. See http://forums.studentdoctor.net /archive/index.php/t-777890.html, retrieved October 9, 2013.

10. See https://sites.tdl.org/fuse/?page _id=128).

11. See https://wiki.library.jhu.edu /download/attachments/9842/PhdBoardPolicy.docx?version=1, last retrieved 10-10-2013.

12. G. P. Clement and F. Rascoe, "ETD Management and Publishing in the ProQuest System and the University Repository: A Comparative Analysis, Journal of Librarianship and Scholarly Communication 1(4):eP1074, http://dx.doi. org/10.7710/2162-3309.1074, p. 24.

13. Ibid.

14. See http://sites.tdl.org/fuse/?page_ id $=372$.

15. See http://manoa.hawaii.edu/graduate/content/submission-publication, retrieved October 2, 2013.

16. R. E. Ellsworth, "Toward publishing doctoral dissertations," The Journal of
Higher Education, 23, 241-244, http://dx.doi. org/10.2307/1976835

17. See www.nsf.gov/statistics/sed/2011 /pdf/tab3.pdf.

18. Julie L. Moore, "Bibliographic Control of American Doctoral Dissertations, Special Libraries (July 1972): 285-91.

19. Gail Clement, "Infographics showing ProQuest ETD coverage is incomplete," http://sites.tdl.org/fuse/?p=757, retrieved October 10, 2013

20. Marlene Coles, CGS Summer Workshop and New Deans Institute, July 15, 2013, San Juan Puerto Rico. Online at www.cgsnet.org /ckfinder/userfiles/files/cgssmr2013_Coles. pdf; retrieved October 1, 2013.

21. Char Miller, "Riding the Wave: Open Access, Digital Publishing, and the Undergraduate Thesis," Pomona Faculty Publications and Research, Paper 377, http:// scholarship.claremont.edu/pomona_fac _pub/377. 2

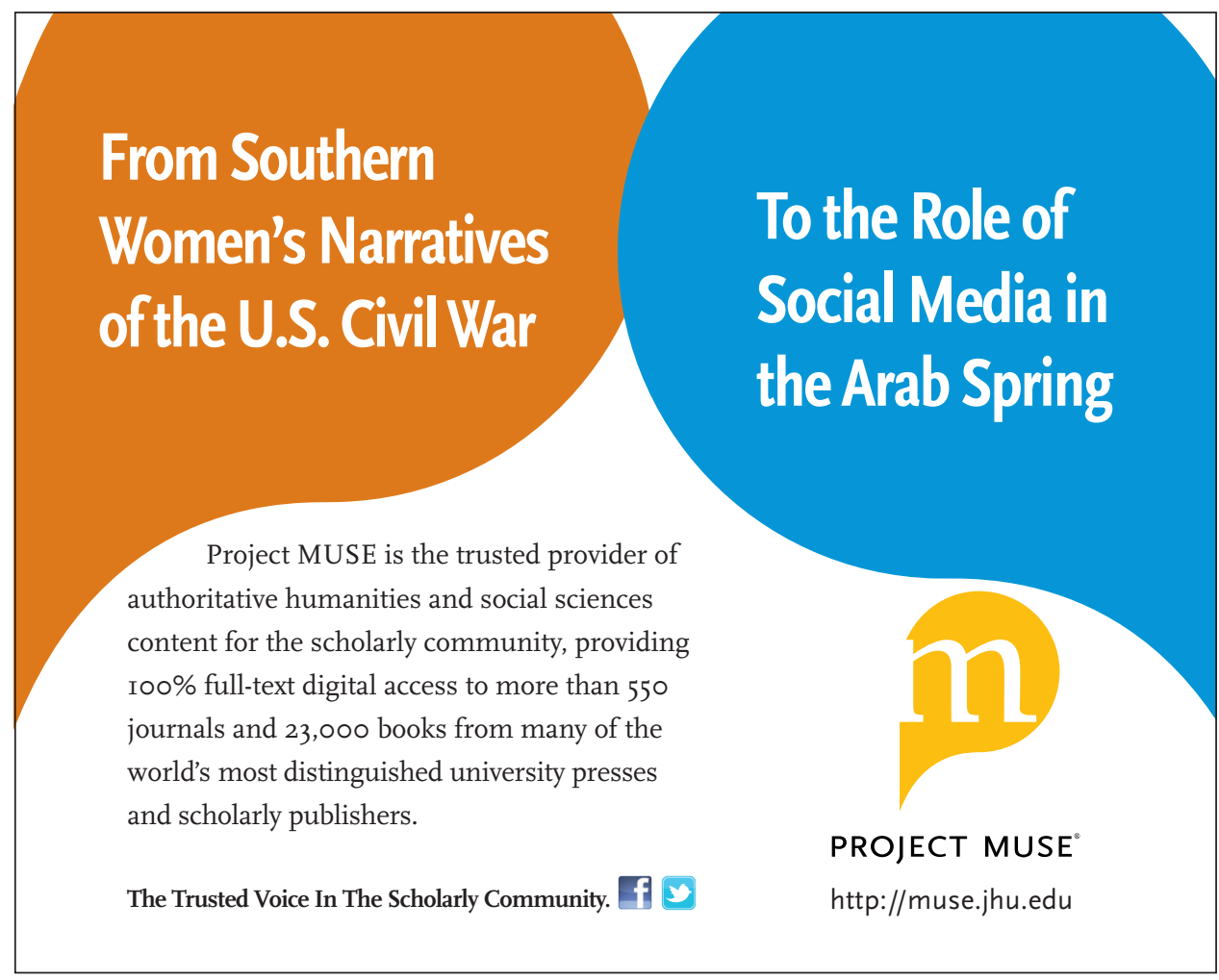

